\title{
RESULTS FROM A RAPID ASSESSMENT OF BRAZILIAN MATERNITY HOSPITALS: ACTIONS TO PREVENT CONGENITAL SYPHILIS
}

Andrea M. B. Beber ${ }^{1}$, Pâmela C. Gaspar ${ }^{1}$, Filipe B. Perini ${ }^{1}$, Mariana V. Martins' ${ }^{1}$, Tatianna M. de Alencar', Francisca Lidiane S. Freitas ${ }^{1}$, Alexsana S. Tresse 1, Fernanda M. Rick ${ }^{1}$, Ana Flávia N.P.C Pires ${ }^{1}$, Adele S. Benzaken ${ }^{1}$

\section{Background:}

In 2017, the Brazilian Ministry of Health (MoH) conducted a rapid assessment survey to be filled by public Brazilian maternity hospitals on prevention of mother-to-child transmission (MTCT) of syphilis and HIV. The aim of this study was to verify syphilis prophylactic measures taken by those health services.

\section{Method:}

This is an analytical, comparative study with a quantitative approach, carried out in a sample of 1,000 Brazilian maternity hospitals. Data were collected through an online questionnaire referring to syphilis testing, treatment of postpartum women and care of newborns exposed to syphilis. The maternity hospitals were categorized in two types: 1 = maternities that perform over 500 deliveries/year $(n=540)$; and $2=$ maternities that perform fewer than 500 deliveries/year $(n=460)$. For data analysis, the Pearson Chi-Square Tests was used.

\section{Results:}

CHART 1- SYPHILIS PROPHYLATIC MEASURES IMPLEMENTED IN BRAZILIAN MATERNITIES, 2018.

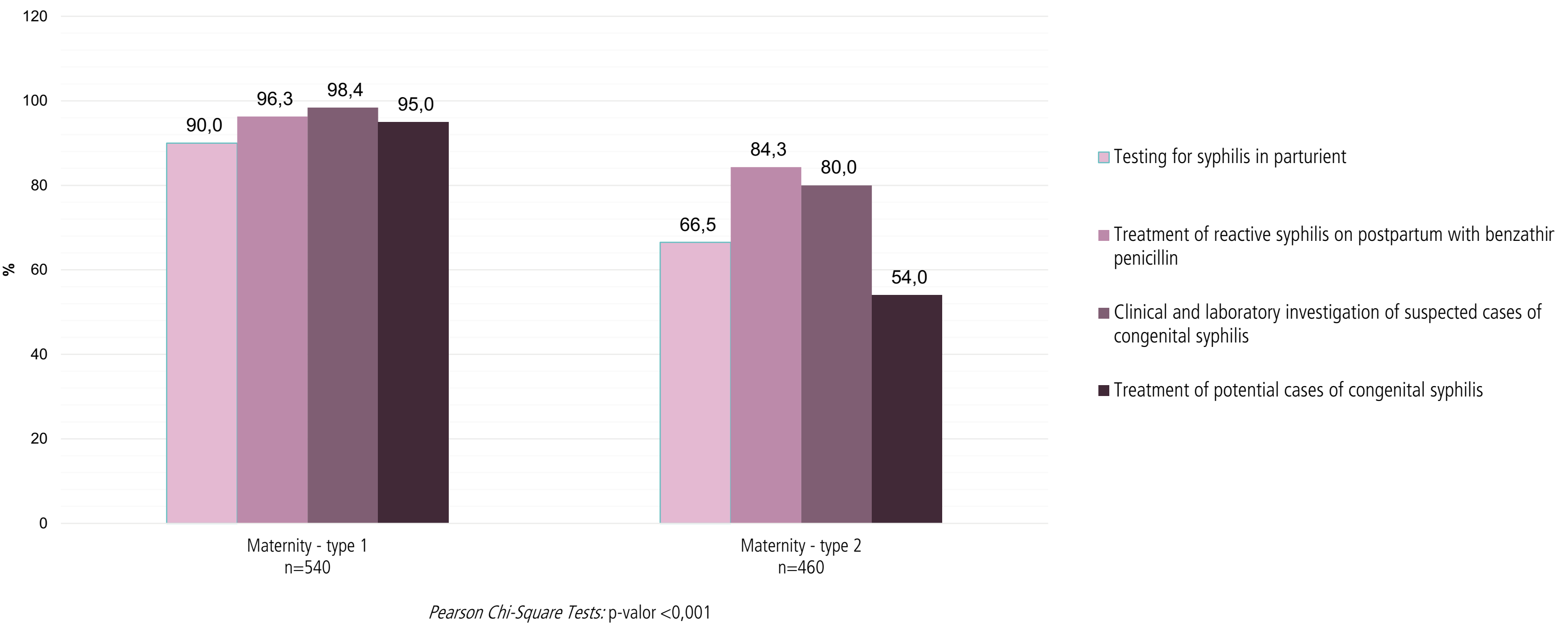

\section{Conclusions:}

Type 1 maternities demonstrated better outcomes related to all syphilis prophylactic measures in comparison to maternities that perform fewer deliveries/year. Type 2 maternities showed low compliance with the recommendations, leading missed opportunities to reduce morbidity and mortality of congenital syphilis in the country. This suggests that similar situational diagnosis tools may be employed annually with the aim of improving strategies, since the questionnaire proved to be an important management tool for directing MoH's public policies towards the MTCTS. 